\title{
LA CONSTRUCCIÓN DE LA FELICIDAD COMO OBJETO DE ESTUDIO Y SU POSIBLE ABORDAJE DESDE EL CAMPO DE LA COMUNICACIÓN
}

\author{
Óscar Julián Cuesta Moreno * \\ DOI: https://doi.org/10.33571/revistaluciernaga.v11n21a7
}

\section{Resumen}

Se presentan los resultados de una revisión de la construcción de la felicidad como objeto de estudio en las ciencias sociales haciendo hincapié en el campo de la comunicación. Se identificó que la felicidad es un concepto polisémico que dificulta su construcción como objeto. No obstante, algunos científicos han determinado indicadores econométricos para abstraerla, corriendo el riesgo de hegemonizar una sola forma de comprender la felicidad. Se concluye que la comunicación tiene un alto potencial de trabajo investigativo y teórico en este tema, ya que puede aportar de manera crítica a la compresión de la felicidad en la sociedad contemporánea. En junio de 2012 la Asamblea General de las Naciones Unidas expresó que la felicidad y el bienestar deben orientar los objetivos de las políticas públicas de los países.

Palabras clave: felicidad; psicología positiva; comunicación.

Recibido. Noviembre 23, 2018

Aceptado. Marzo 12, 2019

*Magister en educación. Profesor del Departamento de Formación de la Pontificia Universidad Javeriana, Bogotá, Colombia. Orcid. https://orcid.org/0000-0001-7181-1183 ; e-mail: ocuesta@javeriana.edu.co 


\title{
THE CONSTRUCTION OF HAPPINESS AS AN OBJECT OF STUDY AND ITS POSSIBLE APPROACH FROM THE SCIENTIFIC FIELD OF COMMUNICATION
}

\author{
Óscar Julián Cuesta Moreno * \\ DOI: https://doi.org/10.33571/revistaluciernaga.v11n21a7
}

\section{Summary}

We present the results of an analysis of the construction of happiness as an object of study in the social sciences, emphasizing the field of communication. It was identified that happiness is a polysemic concept that hinders its construction as an object. However, some scientists have determined econometric indicators to abstract it, running the risk of hegemonizing a single way of understanding happiness. It is concluded that communication has a high potential for investigative and theoretical work in this topic, since it can contribute critically to the understanding of happiness in contemporary society. In June 2012, the General Assembly of the United Nations expressed that happiness and well-being should guide the objectives of the public policies of the countries.

Keywords: happiness; positive psychology; communication.

Received. November 23, 2018

Accepted. March 12, 2019

*Magister en educación. Profesor del Departamento de Formación de la Pontificia Universidad Javeriana, Bogotá, Colombia. Orcid. https://orcid.org/0000-0001-7181-1183 ; e-mail: ocuesta@javeriana.edu.co 


\title{
A CONSTRUÇÃO DA FELICIDADE COMO OBJETO DE ESTUDO E A SUA POSSÍVEL ABORDAGEM A PARTIR DO CAMPO DA COMUNICAÇÃO
}

\author{
Óscar Julián Cuesta Moreno * \\ DOI: https://doi.org/10.33571/revistaluciernaga.v11n21a7
}

\section{Resumo}

São apresentados os resultados de uma revisão da construção da felicidade como objeto de estudo nas ciências sociais com ênfase no campo da comunicação. Identificou-se que a felicidade é um conceito polissêmico que dificulta sua construção como objeto. No entanto, alguns cientistas determinaram indicadores econométricos para abstraí-la, correndo o risco de hegemonizar uma única forma de entender a felicidade. Conclui-se que a comunicação tem um alto potencial de pesquisa e trabalho teórico sobre o tema, pois pode contribuir criticamente para a compreensão da felicidade na sociedade contemporânea.

Palavras-chave: felicidade; psicologia positiva; comunicação.

Recebido. Novembro 23, 2018

Aceito. Março 12, 2019

*Magister en educación. Profesor del Departamento de Formación de la Pontificia Universidad Javeriana, Bogotá, Colombia. Orcid. https://orcid.org/0000-0001-7181-1183 ; e-mail: ocuesta@javeriana.edu.co 


\title{
Introducción
}

Si bien los estudios sobre la felicidad tienen una resonancia en los medios de información, no existe el campo científico único para estudiarla. De hecho, Rojas (2009) afirma:

\begin{abstract}
"Al ser la felicidad un objetivo final para los seres humanos, es sorprendente que no exista ninguna disciplina que se ocupe directamente de su estudio de manera científica; aunque también es cierto que todas las disciplinas suponen que su quehacer científico contribuye, directa o indirectamente, a aumentar el bienestar del ser humano" (p.540).
\end{abstract}

Sin embargo, "en las últimas décadas ha surgido una serie de trabajos que en lugar de pensar en función de utilidad se preguntan qué tan satisfechos o felices están los individuos" (García y Chicaíza, 2013, p. 365). Un buen ejemplo es The World Database of Happiness, un archivo global de investigaciones sobre el tema.

En ese orden de ideas, se puede ver que si bien no existe una única disciplina que tenga por objeto de estudio la felicidad, si hay varias de estas que han vinculado a su saber disciplinar la pregunta por la felicidad o términos que buscan abarcar la satisfacción de las personas con la vida que llevan.

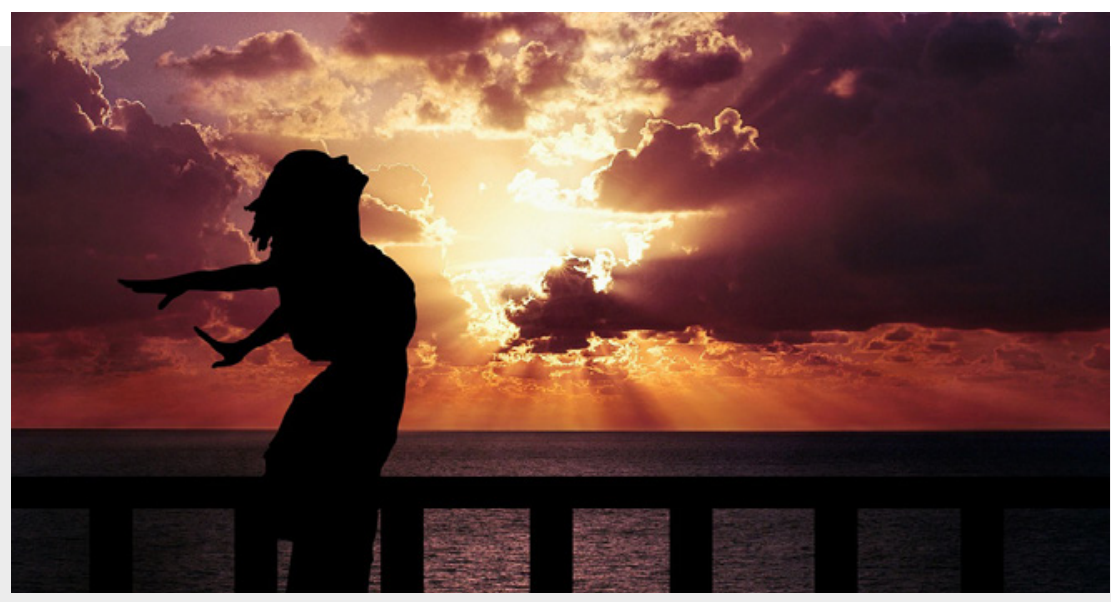

Imagen: https://bit.ly/32×5KGI

Rodríguez et al (2016) muestra que el 68\% de los trabajos publicados sobre la felicidad analiza los factores o causas que influyen en su consecución (el camino para ser feliz). Por su parte, el debate sobre su medición solo es del 14\%; el $8 \%$ habla sobre valores y creencias asociados a ella y el 5,4\% discute teóricamente el concepto. Además:

"es importante resaltar también que la felicidad tiende a ser vista desde la ciencia como un fenómeno finalista, es decir como la variable dependiente a explicar o afectar. En muy pocos casos se utiliza como variable independiente causante de otros fenómenos o se estudian sus consecuencias (sólo el 4,5\% de la literatura)" (Rodríguez et al, 2016, p. 49). 
De hecho, la investigación sobre la felicidad cobra aún más relevancia cuando el Rey de Bután, Sigme Singye Wangchuk, formuló el concepto de Felicidad Interna Bruta (FIB) o Felicidad Nacional Bruta (FNB), puesto que llevó la felicidad a un tema de Estado y, con ello, a pensar metodologías científicas para abstraer un índice. Este hecho se convirtió en referente internacional y generó "esfuerzos importantes para medir el bienestar subjetivo y aplicarlo a sus políticas públicas" (Beytía, 2015, p.61).

Beytía (2015), al analizar estos indicadores, señala la paradoja de los índices de felicidad, dado que algunos países pobres suelen estar por encima de los ricos. Esto ha llevado a un debate permanente sobre la formulación de métodos para medir la felicidad.

No obstante, no se trata de pensar cómo medir la felicidad, sino de debatir una semántica de la felicidad que está haciendo carrera en la sociedad de mercado, entre otras cosas, porque los medios de información han ayudado a hegemonizar sus supuestos. Un buen ejemplo es la idea de que la felicidad es un asunto individual, donde el sujeto debe organizarse emocionalmente para lograr su bienestar. Para ello, en cualquier supermercado encuentra libros de superación personal que le indican cómo "estar bien" a pesar de que el lugar donde trabaje le genera malestar.

En esa línea, Gómez (2017) critica la filosofía de la superación personal, "pues parte de una actitud conformista, que cree que vivimos en el mejor de los mundos posibles y en tal medida al sistema no se le debe cambiar nada, solo hacerle ajustes". Argumenta, que esta filosofía hace creer que "quien fracasa en la sociedad del rendimiento individual se hace responsable a sí mismo, es el único culpable de sus errores" (s.p).

Consecuentemente, es importante analizar que esta filosofía de la superación personal se asocia a una gramática de felicidad donde el sujeto es responsable de su bienestar, dejando de lado una crítica estructural a la sociedad y sus dinámicas económicas.

Es pertinente esta crítica toda vez que la Oxford Happines Inventory "parte de la hipótesis de que las percepciones de felicidad, cambian de región a región, por la influencia que ejercen los factores culturales y las condiciones" (Chicaiza, 2012, p. 41). Es decir, que no existe un único modelo de felicidad y que esta está atada a factores socioculturales que no pueden universalizarse como lo pretende hacer la semántica del orden hegemónico.

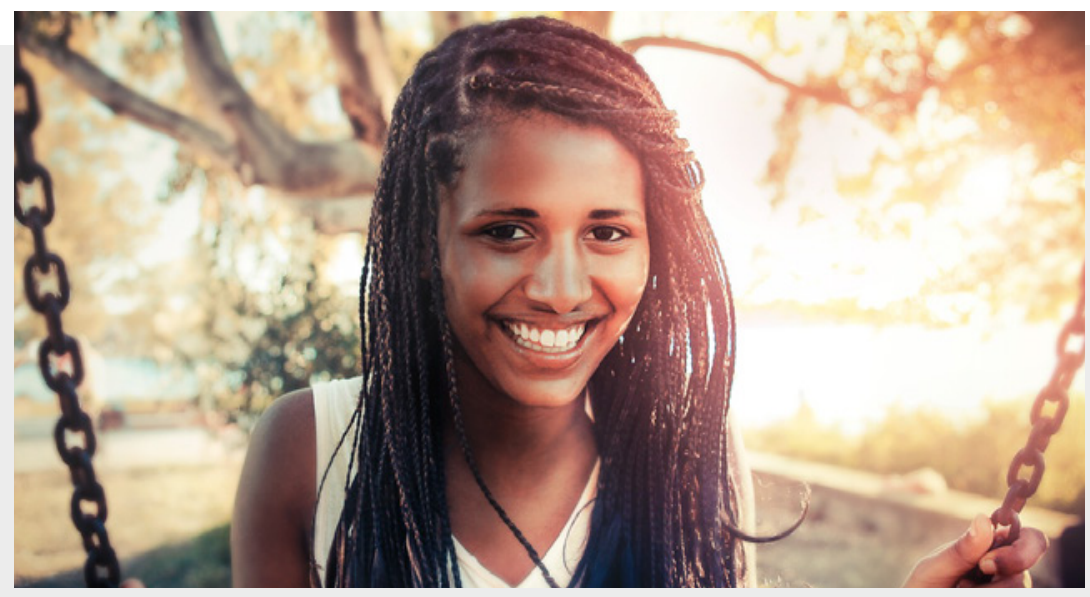


Además, varios autores han señalado que en la sociedad contemporánea la felicidad se asocia al bienestar, intrínseco al mercado: comprando productos y servicio que generan comodidad, placer, éxito, belleza y salud.

Entonces, detrás de la idea de felicidad hegemonizada por los medios de información, la publicidad y organizaciones estatales y no estatales, se advierte un asunto de conducción de subjetividades, para que los sujetos moldeen sus mentes y cuerpos conforme al canon del bienestar ofrecido por el mercado, donde la infelicidad es un asunto de fracaso individual, pues todo está dispuesto para ser feliz, encubriendo que existen problemas estructurales socioeconómicos que limitan las oportunidades para una gran parte de las personas.

Este texto presenta los resultados de una investigación que revisó trabajos de ciencias sociales que abordan la construcción de la felicidad como objeto de estudio, para identificar de qué manera se ha abordado este tema en el campo de la comunicación.

El artículo primero expone la dificultad de construir la felicidad como objeto de estudio, después muestra como ciertos científicos se han valido de indicadores econométricos para abstraerla empíricamente. Existen otros autores que señalan que este tipo de trabajos desconocen la constitución cultural de la felicidad, lo que implica hablar de felicidades. Finalmente, se exponen trabajos que desde el campo de la comunicación han pensado la felicidad, pero se señala la necesidad de profundizar en el tema, ya que se advierte como una línea de alto potencial investigativo y teórico.

\section{Metodología}

Se realizó una revisión documental de carácter descriptivo, determinada por un corte temporal y geográfico. De esta manera, se tuvieron en cuenta trabajos publicados entre el año 2000 y 2017 . Frente al corte geográfico, el estudio contempló documentos académicos de América Latina y España. Solo se tuvieron en cuenta trabajos en español, idioma predominante en la región. La búsqueda se desarrolló con bases en datos virtuales de ciencias sociales. La información se organizó en una matriz que clasificaba los trabajos según su temática.

\section{Resultados y discusión}

En primer lugar, es pertinente decir que la felicidad es un concepto polisémico. Para el campo científico, esta es un reto ya que el concepto debe propender una única representación. Cosa que se complica, toda vez que "Hoy en día las definiciones se han multiplicado y difieren tanto en el significado de la felicidad como en la forma propuesta de alcanzarla" (Beytía, 2015, p. 63). 
Martínez (2008), basado en García Martín (2002), identifica tres grandes grupos de definiciones de la felicidad:

1- Valoración de la vida de los individuos en términos positivos, usualmente relacionada con la noción de satisfacción con la vida como un todo. 2- Definiciones del bienestar subjetivo en las que priman los componentes afectivos positivo y negativo, es decir, se basan en el cálculo que hacen las personas para llegar a un dictamen global acerca de su estado de ánimo. 3- Definiciones que aluden a la felicidad como virtud o gracia, concentrándose principalmente en los aspectos morales, religiosos y filosóficos (Martínez, 2008, p.26).

En general la palabra parte de una asociación positiva: "podemos decir que todas las definiciones y semánticas cotidianas relacionan el concepto con algo preciado para la vida" (Beytía, 2015, p. 64).

Para Beytía y Calvo (2011) "la felicidad es definida como el grado con que una persona aprecia la totalidad de su vida presente de forma positiva y experimenta afectos de tipo placentero" (p.2). Otros autores aseguran que su medición debe "remitir a la vida en general e incorporar tanto pensamientos como sentimientos" (p.2).

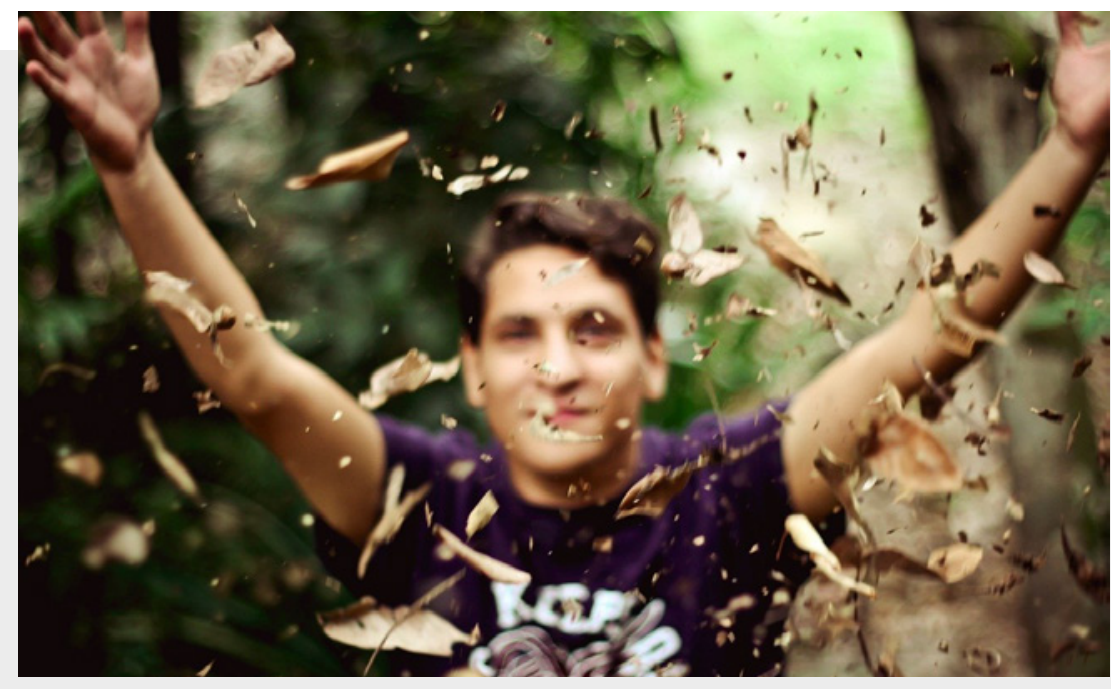

Para Muñiz y Álvarez (2013) la aristotélica eudaimonia "asocia felicidad a un bienestar psicológico surgido de vivir con arreglo a un ideal de perfección humana, esto es, a la virtud" (p.93).

A partir de lo anterior, se puede decir que, si bien la felicidad es una experiencia circunscrita a realizaciones individuales, en los último años tiene una relevancia de corte social (Rodríguez et al, 2016), entre otras cosas, porque su estudio cuenta con variables que establecen la realización del sujeto en su comunidad. En todo caso, como dice Rodríguez et al (2016) al tratar de conceptualizar la felicidad, se definen tareas relacionadas con su diagnóstico y consecución. 
Rodríguez et al (2016) se arriesga a postular que existe un campo de la felicidad, resultado de una configuración científica. "Parece que entramos en una nueva era conceptual alrededor de la felicidad, como nueva dimensión clave de la existencia y vida individual y social" (Rodríguez et al, 2016, p.46).

\title{
2.1 Economía y medición de la felicidad
}

Diferentes disciplinas han indagado sobre la felicidad, pero particularmente es un tema de interés en las ciencias sociales. Por ejemplo, existe un campo denominado "la economía de la felicidad" (EF), que se basa en el "enfoque de bienestar subjetivo", es decir, "preguntar directamente a las personas acerca de su bienestar: la felicidad, la satisfacción de vida o algún concepto relacionado con esto" (Rojas, 2009, p.541).

De hecho, según Vega y Osorio (2016),

\begin{abstract}
"Al entender que la felicidad está correlacionada con la economía, se realizan diversos estudios en este sentido. Por esta razón, la relación entre ingreso y felicidad es significativa [...] Así mismo, la brecha aspiracional influye en la felicidad de las personas, pues sus aspiraciones aumentan a medida que se incrementa el ingreso" (p.7).
\end{abstract}

La felicidad está asociada a juicios subjetivos y, al mismo tiempo, a factores estructurales (economía, cultura, ambiente), es decir, está condicionada a variables subjetivas y objetivas. Esta simultaneidad de factores ha incentivado debates sobre la forma de investigar la felicidad, no obstante, los trabajos tienden a darle preponderancia a variables que inciden en el bienestar de las personas, como la libertad, la salud, el descanso, etc. (Vega y Osorio, 2016). Aliaga et al (2015) dicen que "la felicidad en economía es utilizada como una alternativa de medición del bienestar de las personas, este enfoque empezó con la idea de que la política pública podía aumentar la felicidad de las personas" (pp. 22-23). Básicamente, esto se hace con encuestas que buscan acercarse al nivel de bienestar de los ciudadanos.

De hecho, la asociación de la felicidad a variables económicas a llevado a ciertos estudios a plantear que:

"las personas sienten un mayor grado de felicidad cuando gastan dinero en otras personas y no así en sí mismas, este gasto "bondadoso" hace que los individuos se sientan bien ayudando a otras personas"

(Aliaga et al, 2015, p. 23). 


\subsection{Calidad de vida y felicidad}

Los estudios econométricos y sociológicos han orientado la investigación de la felicidad a indicadores de bienestar subjetivo, ya que "los científicos sociales han encontrado que la felicidad puede ser medida utilizando preguntas sobre la satisfacción con la vida" (Veenhoven, 2013). A veces estos estudios se asocian con el término de calidad de vida.

Para Veenhoven (2001) el término de calidad de vida indica que las distintas cosas que consideramos buenas tienden a coincidir". Este autor piensa que la felicidad hace parte de esta idea. Sin embargo, la conceptualización es compleja ya que "algunas cosas que consideramos buenas pueden incluso reducir la felicidad" (s.p). Por ello, la calidad de vida es más que una construcción conceptual para hacer mediciones y determinar indicadores. Por otro lado, la calidad de vida "se reduce al disfrute subjetivo de esta, a la que se alude normalmente con términos tales como "bienestar subjetivo", "satisfacción en la vida" o "felicidad" en el sentido limitado del término" (Veenhoven, 2009, s.p).

Otro concepto que sale en este entramado econométrico es la felicidad global, que para Veenhoven (2009) puede entenderse como:

"el grado con que una persona juzga favorablemente la calidad global de su propia vida como un todo. En otras palabras: lo que a uno le gusta la vida que lleva" (s.p).

Varios factores para juzgar la propia vida han sido instalados de manera inconsciente en el sujeto, por lo que su apreciación o juicio global puede hablar de una mala o buena vida, pero en el marco de estándares que se creen naturales, como los que logra el mercado imponer con la publicidad.

De allí que sea pertinente sospechar de términos como bienestar subjetivo y satisfacción con la vida como sinónimos de felicidad. De hecho, Martínez (2008) plantea que es imposible discriminar los factores que influyen en la felicidad. La consecución de esta, es una experiencia individual que evalúa a cada persona y se asocia a las oportunidades que ha tenido en su vida. Conceptos como satisfacción personal, bienestar subjetivo o calidad de vida sólo expresan modelos de medición que buscan estandarizar la felicidad, dejando de lado que es un concepto "producto de una construcción histórica que corresponde con el espíritu de los tiempos o el sentido común imperante en una sociedad y época" (Martínez, 2008, p.46).

Para Martínez (2008) esto es preocupante ya que estas mediciones de felicidad sirven para orientar y planificar políticas públicas. Es un problema que la investigación sobre la felicidad tenga por eje la forma de medirla, como si se entendiera bien este concepto. 
Rodríguez et al (2016) muestran como la felicidad deja de ser un asunto de reflexión mística y filosófica, para tener un lugar concreto en el pensamiento, tanto que busca ser concreta, delimita, medible, objetivizada y materializa. En sus palabras, la felicidad se establece como gran meta social, por lo que "se desarrolla una compleja y extensa industria de la felicidad" (p.47).

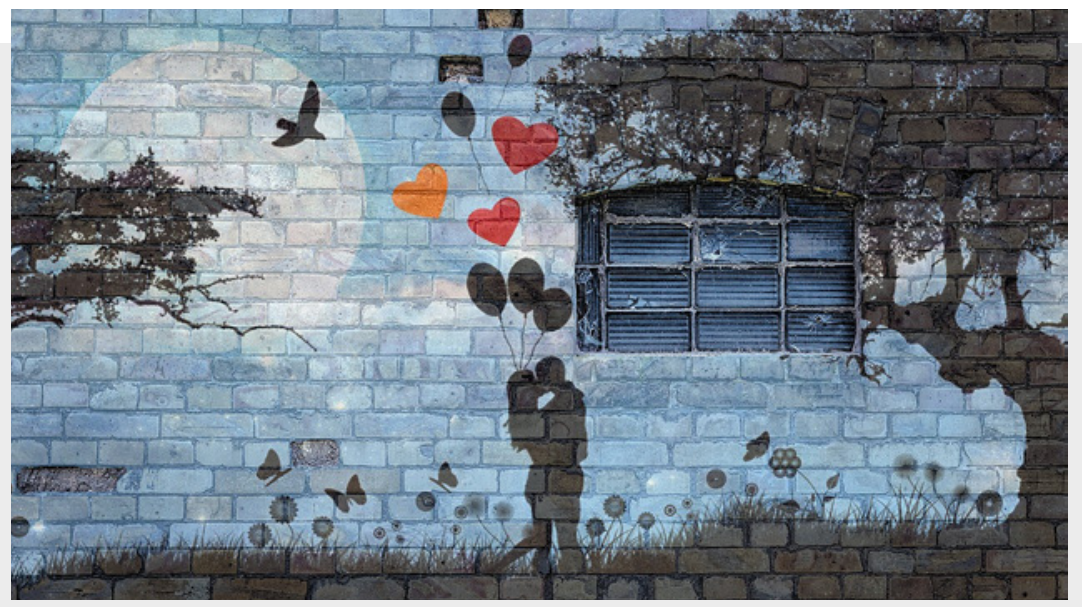

Esta industria combina el sector de bienestar y la satisfacción, que aparentemente procura un distanciamiento de lo material o económico. Por ejemplo, Vega y Osorio (2016) aseguran que "las personas en el mundo sienten mayor satisfacción frente a la vida cuando tienen una buena expectativa de salud, cuando sienten el apoyo de las personas de su entorno y se sienten libres de tomar decisiones" (p.12).

No obstante, la satisfacción con la vida asociada a la salud y el buen entorno afectivo se asocia, así sea de manera parcial, al nivel de ingreso de las personas (Santa, 2012). Entonces, esta industria del bienestar que asocia la felicidad a aspectos no materiales es sostenida, de manera directa, por las relaciones materiales del capital. En efecto, los ingresos monetarios permiten seguridad, educación, salud, ocio, etc.

\subsection{Trabajos de felicidad y comunicación}

La comunicación como campo disciplinar no ha sido ajeno a la investigación sobre la felicidad. De hecho, La Rosa (2012) afirma que la comunicación es importante en el estudio de la felicidad porque cuando alguien está bien lo expresa, "dada la vinculación de las emociones con la comunicación no verbal". Además, porque "una sociedad donde la gente se comunique de manera abierta, intensiva y asertiva reuniría algunas de las condiciones básicas para ser una sociedad feliz" (p.48).

Este autor también vincula la comunicación interpersonal con felicidad, en la medida que una "persona satisfecha, le da sentido a su existencia, y esto lo trasmite mediante sus palabras y su propia conducta" (p.49). 
De allí que entornos donde exista una comunicación fluida y con libertad de expresión contribuyen a la felicidad (La Rosa, 2012). Además, se asocia la comunicación con 9 dominios y 33 indicadores de la felicidad Nacional Bruta planteado por el Rey de Bután. Entre otros, la comunicación se articula a la resiliencia, la comunidad, buen gobierno, diversidad cultural, educación, familia.

Muñiz y Álvarez (2013), siguiendo la propuesta en boga de la psicología positiva de Martin E. P. Seligman, hablan de una comunicación positiva, que definen como "aquella comunicación organizacional que, al margen de otros objetivos, fomenta consciente o inconscientemente la felicidad y el bienestar psicológico de los públicos a los que se dirija" (p.90). Afirman que la comunicación tiene un vínculo intrínseco con la felicidad, toda vez que sostiene muchas de las virtudes y fortalezas que diferentes autores han señalado para ser feliz.

Puntualmente, se entiende comunicación positiva como la orientada a "mejorar el grado de bienestar psicológico o felicidad eudaimónica del conjunto de receptores, independientemente de si dicha comunicación alberga objetivos de otra índole, sean estos eminentemente persuasivos, informativos, o de entretenimiento" (Muñiz y Álvarez, 2013, p.94), ya sea a nivel interpersonal, organizacional o empresarial. Plantean que "una empresa eudaimónicamente feliz será, por tanto, aquella que cuente con miembros mayoritariamente felices" (p.95).

Jordá (2013), tomando una posición crítica, señala que "las marcas, todos los productos y servicios ofrecen la felicidad como ventaja de compra principal" (p.16). Para vender el concepto de felicidad, "hablan explícitamente [y] de forma implícita a través de la actitud de los personajes que aparecen en las escenas del anuncio, bien sea a través de gestos de felicidad o del concepto de éxito" (p.19).

Por su parte, Chicaiza (2012) dice que "buena parte de los productos, sus deseos de posesión y adquisiciones no responden a necesidades fisiológicas, sino sociales, de autorrealización y entre ellas aparece, lo que muchos consideramos indiscutible: la imparable búsqueda de la felicidad" (p.38). Entonces, bajo estas condiciones, "la felicidad se encuentra vinculada a las estrategias comunicacionales persuasivas de las marcas tanto de productos y servicios" (Chicaiza, 2012, p. 39).

En últimas, las marcas buscan llegar a la gente con la idea de bienestar y prosperidad individual. La ilusión de prosperidad esta asociada a adquirir cosas, que a lo que llevan es a una ansiedad permanente (Chicaiza, 2012). Así, "la marca está asociada a valores que simbolizan los estilos de vida "más felices". En general, para Chicaiza (2012), la idea de felicidad que predomina asocia a las marcas "con la sensación de control, la cognición positiva, los afectos positivos y el buen estado físico" (p.48). 


\subsection{El predominio de la felicidad asociada a la psicología positiva}

Se advierte que la psicología influye mucho en la construcción de la felicidad, ya que su discurso y análisis se centra en el individuo y no en lo colectivo (Martínez, 2008). .

Rodríguez (2014) señala que a veces estos estudios "son manipulados por la industria del consumo" que los homologa "casi totalmente con la imagen pragmática de éxito social" (p.301). Esto último tiene consecuencias importantes, pues centra la felicidad a una búsqueda individual "desatendiendo las responsabilidades compartidas de las personas y las instituciones en la construcción de mundo, minimizando los efectos de estructuras sociales como la exclusión o la injusticia, sobre todo en contextos donde estos [significados de felicidad] se han naturalizado, como es el caso de los países de Latinoamérica" (Rodríguez, 2014, p.301).

De hecho, Roque (2011) considera que al ser la felicidad un significante que "obedece a diferentes contextos histórico-socio-políticos", se presta fácilmente a usarlo "como un dispositivo de poder, para promover las ideologías que obedecen a las estructuras hegemónicas" (p.iv).

Por ello, algunos autores concedieran que la psicología positiva, sustentada como ciencia, construye una realidad donde los sujetos tienen las mismas características. Por tal, para lograr la felicidad se establece un camino, una serie de consejos, que son universales, es decir, que no dependen de la individualidad. Esto coloca en lugar de poder al que tiene el secreto, al psicólogo, al autor de libros de autoayuda, al experto en coaching, etc.

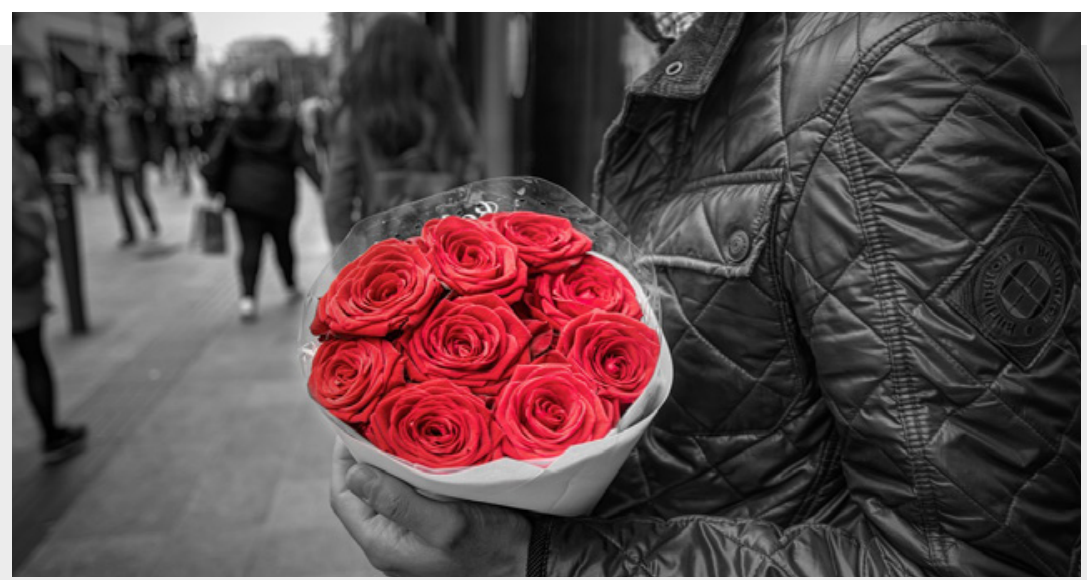


La idea de felicidad postulada por la psicología positiva no es ajena a su contexto de enunciación, esto es, el capitalismo de mercado. De allí que para Roque (2011) esta psicología "alberga un mensaje de conformismo con la situación de vida para sentirse satisfecho, finalmente feliz" (p.65).

En efecto, las exportaciones de la psicología positiva orientan al sujeto a prácticas de agradecimiento y relajación que parten de la aceptación pero, peligrosamente, se pueden quedar en estados de resignación sonriente. Desconociendo la potestad del sujeto en la construcción de las estructuras sociales y su poder de agenciamiento.

El discurso de la psicología positiva tácitamente expresa que el sujeto infeliz es culpable de su estado, incluso, da entender que es obligación de todos estar felices, por lo que es obligación siempre experimentar emociones positivas (Roque, 2011), desconociendo la naturaleza humana, que de por si es abierta a múltiples emociones que tienen interpretaciones de acuerdos a esquemas construidos subjetivamente.

La psicología positiva simplifica a la clasificación social, toda vez que "dicotomiza al ser humano y lo clasifica como feliz o infeliz" (Roque, 2011, p.67), promoviendo el individualismo que, por demás, es necesario en el capitalismo. Para Roque (2011) esta imposición de estar siempre felices y positivos, de mirar siempre el lado bueno de las cosas, puede tener consecuencias negativas: "Si te sientes mal por algo y no puedes poner una cara feliz aunque lo intentes, puedes llegar a sentirte incluso peor" (p.68). En otras palabras, sentirse culpable por no estar bien, genera grandes conflictos intra-subjetivos que pueden llevar a estrés y otras reacciones. El significado de la felicidad que siembra esta psicología simplifica la experiencia humana (Roque, 2011). Como se ha señalado, la felicidad es una construcción, cultural e histórica, que no puede naturalizarse como lo pretenden estos discursos, por lo que no hay caminos o formulas absolutas para alcanzarla.

Además, al ser la felicidad una construcción cultural e histórica, es decir, discursiva, no está ajena a relaciones de poder. De hecho, es lo que se ve hoy con la psicología positiva y los libros de auto ayuda: un discurso que se ha impuesto porque es conveniente para el capitalismo, toda vez que coloca el malestar como un problema del individuo y no estructural o sistémico.

Para finalizar, Oxa, Arancibia y Campero (2014) consideran que la felicidad experimentada por las personas depende de muchos factores, que varían entre la dimensión subjetiva y las diferentes concepciones de felicidad, además, entre el género, la edad, el nivel de educación, las creencias religiosas, las condiciones laborales, la salud, etc. Así, es pertinente reiterar que no puede existir un único canon sobre ser feliz.

No obstante, lo que se ve es que se ha impuesto una suerte de unidad semántica de la felicidad que determina formas de estudiarla y, sobre todo, que agenda técnicas para alcanzarla. Esta semántica es tributaria al orden económico vigente toda vez que su no consecuencia es un asunto del individuo y no de las estructuras socioeconómicas. Para lograr esta imposición, el orden recurre, entre otras cosas, a los discursos, de allí que sea importante analizar si las construcciones periodísticas subsidian o reproducen la imposición de esta felicidad del capitalismo de mercado. 


\section{Conclusiones}

En los últimos años se ha venido incrementando el estudio científico sobre la felicidad. Entre otras cosas, este se explica porque los Estados tienen hoy como eje de sus políticas el bienestar y satisfacción subjetiva, conceptos asociados a la medición econométrica de la felicidad. Además, estas investigaciones pasan rápidamente al mercado de la felicidad, como lo son los libros de autoayuda, muchos de ellos sostenidos por discursos de la psicología positiva. En noticieros de radio, televisión, periódicos y revistas se abordan los resultados de estas investigaciones sobre la felicidad de manera cotidiana, haciendo hincapié en los pasos o consejos que se deben seguir para alcanzarla. Sin embargo, al divulgar esta información muchas veces se reproduce un discurso sobre la felicidad que es subsidiario del sistema socioeconómico neoliberal, desconociendo otras formas de felicidad ancladas a prácticas culturales diferentes a dicho modelo.

Por ello, es importante investigar por qué y cómo la felicidad se establece como objeto de estudios en las ciencias sociales y humanas. En primer lugar, porque si bien "la felicidad desde épocas muy antiguas ha merecido el interés de los filósofos [...] no había representado hasta hace relativamente poco tiempo, tema de interés para la investigación científica" (La Rosa, 2012, p. 42). En ese orden, siguiendo a Rojas (2009), existe un reto académico de ampliar el conocimiento sobre la felicidad pues es un concepto asociado a la experiencia de las personas.

Es importante investigar sobre le felicidad porque es un asunto relativamente reciente en el campo científico, además porque una ampliación en su conocimiento permite "hacer recomendaciones de política pública y de organización social que contribuyan al aumento del bienestar de los seres humanos" (Rojas, 2009, p. 542). De hecho, Beytía (2015) señala "que es deseable que los Estados nacionales consideren la felicidad de su población como uno de los factores relevantes en la orientación de sus políticas públicas" (p.62). Esto lo ha reiterado Veenhoven (2013), quien plantea unas políticas para lograr una mayor felicidad para más número de personas. Aún más, en junio de 2012 la Asamblea General de las Naciones Unidas expresó que la felicidad y el bienestar deben orientar los objetivos de las políticas públicas de los países.

Se observa una necesidad de aumentar el conocimiento científico de la felicidad y, con este, planificar políticas para llevar a los ciudadanos a alcanzarla. Visto así, un proyecto que analice la felicidad desde el campo académico de la comunicación aporta a un debate contemporáneo a nivel científico y puede incidir en la formulación de lo público. Muñiz y Álvarez (2013) afirman que "Si bien las posibilidades de confluencia entre felicidad humana y comunicación aún están en un estado incipiente, parece haber por delante un enorme y prometedor terreno por explorar" (p.90).

A esto se suma que es importante analizar cómo los mensajes masivos posicionan discursos de la felicidad que organizan ideales sociales, por ejemplo, que colocan la productividad como variable de bienestar, hecho que puede ser altamente perjudicial toda vez que hay estudios que muestra como la productividad puede afectar relaciones familiares y sociales lo que reduciría la felicidad (Aliaga, Gantier y Herrera, 2015). 


\section{Referencias}

Aliaga Lordemann, J., Gantier Mita, M., \& Herrera Jiménez, A. (2015). Productividad y Felicidad: $¿$ Las Personas más Productivas son más Felices?(No. 13/2015).

Aliaga, J. Herrera, A. Gantier, M. Serrudo, L. Carvajal, M. (2015). Avances de la economía de la felicidad en bolivia. En línea:

http://www2.hss.de/fileadmin/americala tina/Bolivia/downloads/Libro_economia felicidad.PDF.

Amaro La Rosa (2012). Comunicación y felicidad. En: Rosario Alarcón Alarcón (Dir.). Psicología positiva. La Molina: Universidad Femenina del Sagrado Corazón - UNIFÉ39-54.

Beytía, P. (2015). El potencial político de la felicidad: fundamentos científicos y de aplicación gubernamental. Persona Y Sociedad, Vol. XXIX / N³ 3, pp. 59-86.

Beytía, P., Calvo, E. (2011). ¿Cómo medir la felicidad? Claves para Políticas Públicas 4, 1-10.

Cuesta, O. y Lora, M. (2015). La mediación creativa. Un acercamiento a su construcción conceptual. Revista Luciérnaga/Comunicación, Año 7 (14). Págs. 46-63. Disponible en: http://revistas.elpoli.edu.co/index.php/l uc/article/view/818.

Chicaiza, Tania. 2012. "Vendiendo felicidad: el nuevo paradigma de las marcas", en: Revista Retos, Año 2, Núm. 3, pp. 37-50.

García Molina, Mario; Chicaíza Becerra, Liliana Alejandra. (2013). Felicidad: ¿reemplazar o mejorar la utilidad subjetiva? Cuadernos de Economía, vol. XXXII, núm. 60, julio-diciembre, pp. 363-368

Gómez, J. (2017). El engaño de la 'superación personal'. El Espectador. En línea:

http://www.elespectador.com/opinion/e l-engano-de-la-superacion-personal-colu mna-706103.

Grajales, D. (2015). La felicidad según Veenhoven. En línea

http://www.elmundo.com/portal/cultura /cultural/la_felicidad_segun_veenhoven. php\#.WZluptLyiig.
Jordá, M.,Teresa Pellicer. (2013). La promesa de felicidad en los mensajes de la publicidad comercial/The promise of happiness in the messages of commercial publicity. Pensar La Publicidad, 7(1), 13-23.

Martínez, E. (2008). Una mirada sociológica en el estudio de la felicidad: en respuesta a ruut veenhoven. En línea: http://eva.fcs.edu.uy/pluginfile.php/775 01/mod_folder/content/0/1-Textos\%20o bligatorios/Oblig38Mart\%C3\%ADnezAl varez2008UnamiradasociologicaFelicida d.pdf?forcedownload=1.

Muñiz-Velázquez, J. A., \& Álvarez-Nobell, A. (2013). Comunicación positiva: la comunicación organizacional al servicio de la felicidad. Vivat Academia, 15(124), 90-109.

Oxa Gerónimo, Alcides Valentín Arancibia Romero, Cristina, \& Campero Encinas, Sergio. (2014). Economía de la Felicidad: evidencia empírica para Latinoamérica. Revista Perspectivas, (34), 159-180.

Rodríguez Díaz José Antonio; Yter Gimeno, Mireia; Arroyo Moliner, Liliana; (2016). El campo de definición de la felicidad por las Ciencias Sociales: una aproximación desde el Análisis de Redes Sociales. Redes. Revista Hispana para el Análisis de Redes Sociales, Vol.27,\#2. 45-71

Rodríguez, M. (2014). Reflexiones sobre desarrollo humano: diálogo entre el estudio de las representaciones sociales de la noción de felicidad y los discursos expertos en psicología positiva. En: Memorias del Primer Encuentro Latinoamericano de Investigación en Psicología. Neiva: Universidad Cooperativa de Colombia. Pp 285-305.

Rojas, M. (2009). Economía de la felicidad. El Trimestre Económico, vol. LXXVI (3), núm. 303, pp. 537-573.

Roque, B. (2011). La psicología positiva como texto: análisis crítico del discurso de la felicidad. [tesis doctoral]. Gurabo: Universidad del Turabo.

Santa, L. Fernández, J. (2012). Felicidad desigualdad, religión y capital social, Revista Economicus Heterodoxus, No.1, pp.11-32. 
Veenhoven, R. (2001). Calidad de vida y felicidad: no es exactamente lo mismo. Centro Scientifico Editore, pp. 67-95.

Veenhoven, R. (2013). Más felicidad para un mayor número de personas ¿Es posible esto en México? En: Ranking de Felicidad en México, Manzanilla-Prieto F. (Ed.), Universidad Popular Autónoma del Estado de Puebla, pp. 33-53.
Veenhoven, Ruut. (2009). Medidas de la Felicidad Nacional Bruta. Psychosocial Intervention, 18(3), 279-299.

Vega, L. Osorio, A. (2016). Economía de la felicidad: bienestar subjetivo y objetivo. Revista Plout0s. Vol. 6, Núm. 2, 4 $-13$.

Para citar este artículo:

Cuesta Moreno, Óscar Julián (2019). La construcción de la felicidad como objeto de estudio y su posible abordaje desde el campo de la comunicación. Revista Luciérnaga Comunicación. Vol. 11, Núm. 21. Pp 140 - 155.

DOI: https://doi.org/10.33571/revistaluciernaga.v11n21a7

OJS. http://revistas.elpoli.edu.co/index.php/luc/issue/archive Link. https://www.politecnicojic.edu.co/index.php/revista-luciernaga 